\title{
Age changes in Rhesus Monkey Ciliary Muscle: Light and Electron Microscopy
}

\author{
Elke LütJen-Drecoll* $\ddagger$, Ernst Tamm*and Paul L. Kaufman† \\ * Department of Anatomy, University of Erlangen-Nürnberg, Krankenhausstrasse 9. \\ D-8.520 Erlangen, Federal Republic of Germany, and † Department of Ophthalmology. \\ University of Wisconsin, Madison, Wisconsin. L.S.A.
}

(Received 18 May 1988 and accepted 6 July 1988)

\begin{abstract}
The ciliary muscle from 44 rhesus monkeys ranging in age from 137-day fetuses and a 3-week neonate to 35-year-old adults was studied by light and electron microscopy. In the fetuses and the neonate, the muscle cells appeared immature, and the muscle consisted mainly of longitudinally oriented fibers. By age 1 year, the muscle fibers were aggregated into bundles, and within each bundle the individual fibers were packed tightly together. In saggital section, the muscle now exhibited longitudinal, reticular and circular portions. The individual muscle cells exhibited ultrastructural characteristics which set them apart from other smooth muscle cells. Age-related structural changes occurred in the ciliary muscle and intramuscular nerves, beginning at 6 years. These included increasing numbers of lysosomes, 'fingerprints', and the appearance of myelin figures within some nerve endings and nerve fibers. These alterations berame more frequent and pronounced with age, and in elderly animals were seen in all regions of the muscle and around its entire circumference. Additionally, the elderly animals exhibited overt degeneration of some muscle cells and some myelinated nerve fibers. The time-course of these age-related structural neuromuscular alterations parallels the decline of functional accommodative amplitude (i.e. presbyopia) and of the ciliary muscle's configurational response to peripheral pharmacologic and central electrical stimulation. This suggests a pathophysiologic, albeit (given the relatively moderate overall abnormalities) not necessarily causal, relationship. An age - related increase in the number of pigmented cells between the ciliary muscle bundles also occurred, with the anterior longitudinal region being affected last. 'This might reflect an agerelated decline in uveoseleral drainage of aqueous humor.

Key words: accommodation; aging: ciliary muscle; presbyopia: rhesus monkey; uveoscleral outflow.
\end{abstract}

\section{Introduction}

The rhesus monkey appears to be a good animal model for human accommodation (Bito. DeRousseau, Kaufman, and Bito, 1982; Kaufman, Bito and DeRousseau, 1983; Neider, Crawford, True-Gabelt, Kaufman and Bito, 1986; Bito, Kaufman, Neider, Miranda and Antal, 1987), presbyopia (Bito et al., 1982; Kaufman et al., 1983, Neider et al., 1986; Bito et al., 1987), and senile cataractogenesis (Kaufman and Bito, 1982) and may also develop ocular hypertension and open angle glaucoma (Kaufman and Bito, 1982). We have previously reported that with age, the ciliary muscle in the intact rhesus eye loses its configurational responses to pilocarpine (Lütjen-Drecoll, Tamm and Kaufman, 1988) and to electrical stimulation of the Edinger-Westphal nucleus (Neider et al., 1986; Bito et al., 1987), despite the fact that by light microscopy only minimal changes are seen in the muscle fibers and the intramuscular connective tissue (Liitjen-Dreeoll et al., in press).

In the present report we describe and quantitate by light and electron microscopy the presence or absence of various age-related alterations in the neuromuscular and connective tissue elements of the rhesus ciliary muscle, which may be relevant to the

‡ To whom requests for reprints should be addressed. 
muscle's loss of responsiveness to pilocarpine and central stimulation, and perhaps to the development of presbyopia. We also describe the age-related presence and localization of pigmented cells within the intramuscular spaces, which may reflect alterations in aqueous humor dynamics.

\section{Materials and Methods}

Forty-four rhesus monkeys (Macaca mulatta) of both sexes, ranging in age from 137-day fetuses and a 3-week (wk) neonate to 35-year(yr)-old adults were studied. All but one were from caged colonies on the University of Wisconsin-Madison campus; most belonged to the Wisconsin Regional Primate Research Center or the Primate Laboratory of the Psychology Department. Many had long and varied non-ocular experimental histories, often involving major medical and/or surgical manipulation of their sex hormones and reproductive physiology. Seventeen animals had previously undergone ocular studies (Bito et al., 1982; Kaufman and Bito, 1982 ; Kaufman et al., 1983), including measurement of accommodative amplitude induced by topical cholinomimetic drugs. Although this subsample was not uniformly distributed throughout the age range (five $>30 \mathrm{yr}$ and ten $20-30 \mathrm{yr}$, but only two $15-20 \mathrm{yr}$ and no younger animals), the available refraction, accommodation and lens clarity data were comparable to those from the larger sample of similarly aged animals in the colony. No ocular abnormalities other than senile cataract and peripheral cystoid retinal degeneration in the oldest animals were seen elinically or histopathologically.

In general, the young and middle-aged animals were sacrificed in conjunction with various non-ocular experimental protocols, while the elderly animals were debilitated and were euthanized to spare them suffering. A few animals expired during or shortly after major nonocular surgery under endotracheal halothane anesthesia, and the 3-wk-old infant was euthanized because of debilitation resulting from maternal rejection. Most eyes were cnucleated in vivo, bisceted cquatorially, quadrisected anteriorly leaving the lens attached to the ciliary body via the zonule in one quadrant. and immersed in Ito's fixative solution (Ito and Karnovsky, 1968). No more than $10 \mathrm{~min}$ elapsed from the moment the globe was lifted free until all tissue segments had been placed in fixative. For the few eyes enucleated immediately post-mortem, up to $30 \mathrm{~min}$ transpired until all pieces entered the fixative. In 15 cases, the eyes were pretreated topically in vivo with either pilocarpine or atropine, for additional studies (Lütjen-Drecoll el al., in press); five of these 15 were initially fixed by perfusion from the left ventricle. Anesthesia for in vivo enucleation and systemic perfusion was i.m. ketamine $15 \mathrm{mg} \mathrm{kg}^{-1}$ followed by i.v. pentobarbital $\mathrm{Na} 25 \mathrm{mg} \mathrm{kg}^{-1}$. Anesthetized animals were euthanized by exsanguination or pentobarbital overdose.

The tissue was flown to Germany in fixative and processed for light and transmission electron microscopy (Lütjen-Drecoll, 1973). Semi-thin sagittal sections, containing iris and ciliary body as far posteriorly as the ora serrata, were made from each Epon-embedded specimen. Ten semi-thin sections per eye were examined, one section from each of ten regions covering the available part of the circumference.

Initially, sections from both eyes of all $\mathbf{4 4}$ monkeys were subjectively evaluated by light microscopy. Sixty-four eyes of 32 animals were then selected for further quantitative light microscopic studies, based on age and fixation quality. From all 10 sections of the chosen eyes were recorded the magnitude and location within the ciliary muscle of: (1) hyalinization or increased amounts of connective tissue between the muscle bundles; (2) increased numbers of pigmented cells between the muscle bundles; (3) lysosomes within the muscle fibers; (4) nerve fiber degeneration. No differences between contralateral eyes of an individual animal were apparent by light microscopy, so all 20 sections from the two eyes were used for the semiquantitative analysis of Table I. In 20 eyes from 20 animals showing the best fixation and spanning the entire age range. ultra-thin sections were cut from four different regions of the ciliary muscle (the anterior longitudinal, inner circular, outer reticular and posterior portions), and evaluated by electron microscopy. In 11 of these 20 eyes, 100 muscle fibers in each region were evaluated quantitatively at $\times 10000$ magnification for 'fingerprints' (circular aggregations of double membranes arranged concentrically, resembling a 'fingerprint' or snail shell) and lysosomes (Table II). Swollen mitochondria and vacuoles were also 


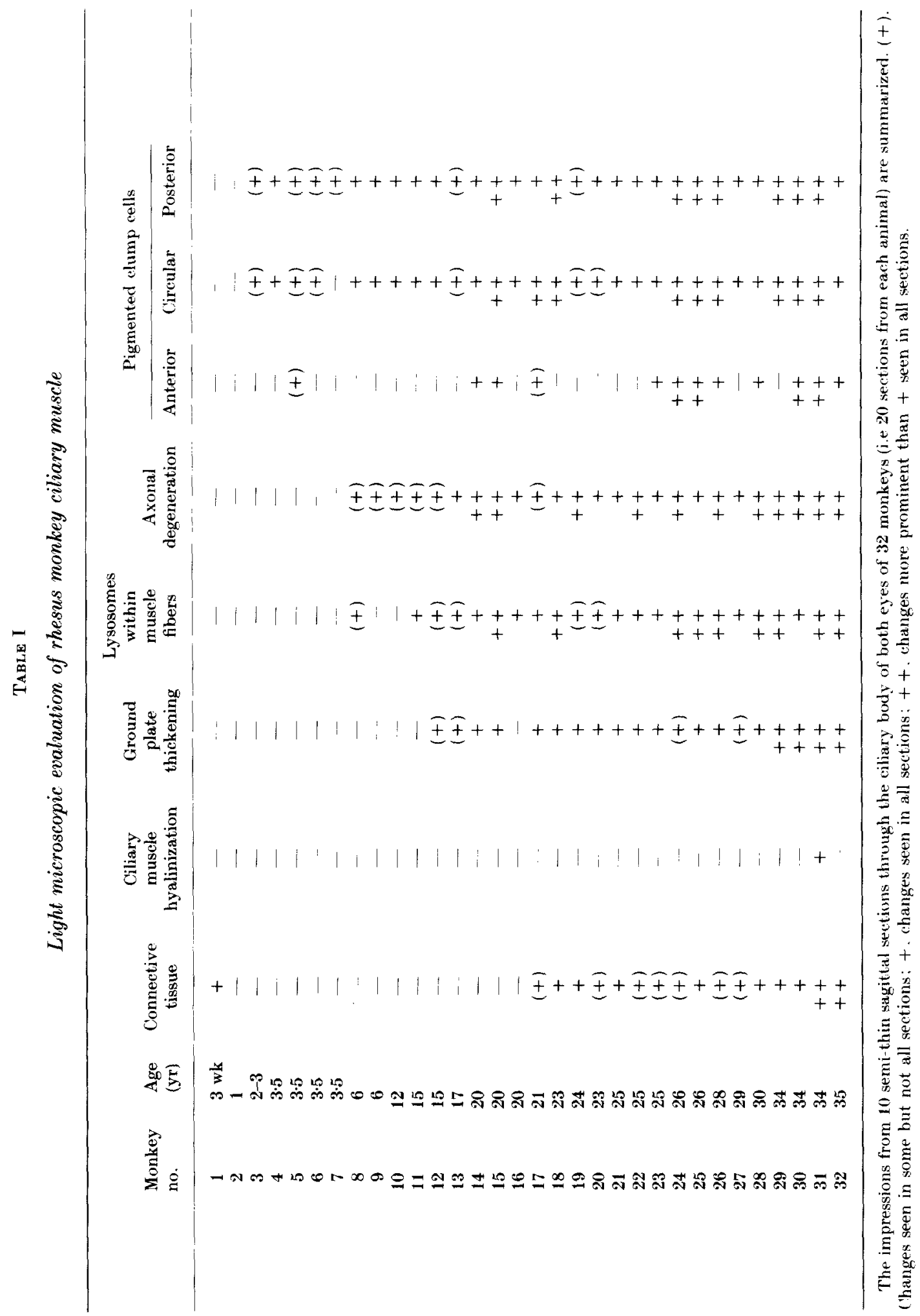


TABLE II

Electron microscopic evaluation of rhesus monkey ciliary muscle

\begin{tabular}{|c|c|c|c|c|c|c|c|c|c|}
\hline \multirow{2}{*}{$\begin{array}{l}\text { Monkey } \\
\text { no. }\end{array}$} & \multirow{2}{*}{$\begin{array}{l}\text { Age } \\
\text { (yr) }\end{array}$} & \multicolumn{2}{|c|}{ Longitudinal } & \multicolumn{2}{|c|}{ Posterior } & \multicolumn{2}{|c|}{ Reticular } & \multicolumn{2}{|c|}{ Circular } \\
\hline & & $\mathrm{F}$ & $\mathrm{L}$ & F & $\mathrm{L}$ & $\mathrm{F}$ & $\mathbf{L}$ & $\mathbf{F}$ & $\mathbf{L}$ \\
\hline 1 & $3 \mathrm{wk}$ & 0 & 0 & 0 & 0 & 0 & 0 & 0 & 0 \\
\hline 2 & 1 & 0 & 0 & 0 & 0 & 0 & 0 & 0 & 0 \\
\hline 3 & $2-3$ & 0 & 0 & 0 & 4 & 0 & 0 & 0 & 0 \\
\hline 4 & $3 \cdot 5$ & 0 & 0 & 0 & 6 & 0 & 2 & 0 & 6 \\
\hline 8 & 6 & 0 & 0 & 0 & 6 & 0 & 6 & 2 & 12 \\
\hline 9 & 6 & 0 & 0 & 3 & 6 & 2 & 4 & 4 & 2 \\
\hline 10 & 12 & 0 & 6 & 0 & 80 & 2 & 10 & 0 & 30 \\
\hline 21 & 25 & 0 & 2 & 2 & 20 & 8 & 16 & 2 & 8 \\
\hline 24 & 26 & 2 & 2 & 2 & 24 & 16 & 16 & 0 & 16 \\
\hline 28 & 30 & 0 & 6 & 0 & 44 & 10 & 18 & 2 & 0 \\
\hline 32 & 35 & 2 & 6 & 1 & 40 & 8 & 26 & 2 & 20 \\
\hline
\end{tabular}

Percentage of muscle cells containing 'fingerprint-like 'structures (F) or lysosomes (L), based on electron microscopic study of 100 muscle cells in ultra-thin sections from the anterior longitudinal, posterior, reticular and circular portions of the ciliary muscle.

counted, but were not listed in the table because these parameters were too dependent on the fixation and post-mortem autolysis. The investigators evaluating the sections (EL-D and ET) were masked as to the age of the animals.

These experiments were conducted in accordance with the ARVO Resolution on the Use of Animals in Research.

\section{Results}

\section{Muscle and nerve tissue}

Age 137 days fetuses - 3-wk-neonate. Histologically, in both fetuses and the neonate, the individual muscle fibers were oriented primarily longitudinally. Three or four fibers were grouped into thin bundles which were clearly separated from each other by large amounts of mesenchymal tissue (Fig. 1(A)). The anterior fiber tips were not yet attached to the embryonal trabecular meshwork; regionalization into longitudinal, reticular and circular portions was incomplete; and the muscle's inner apex was absent (Fig. 1(A)).

Ultrastructurally, the ciliary muscle cells in the fetuses (Fig. 1(B)) resembled the smooth muscle cells seen in the media of vessels. They showed only few mitochondria distributed unevenly between densely packed myofibrils. The myofibrils were attached to the cell membrane by flat, dense bodies and the muscle cells were attached to each other by desmosomes. The muscle cells were surrounded by a thin basement membrane. Within a bundle, the basement membranes of the muscle cells were connected to each other by sparse, thin collagen fibers. Between the different muscle bundles, numerous fibroblasts with cysterns of rough endoplasmic reticulum (ER) and elaborate Golgi membranes were seen. Only few nerve endings were seen within the intramuscular spaces (Fig. 1(B)).

In the 3-wk-old animals, the quantity of collagen fibers between the muscle bundles was increased as were the number of nerve endings. The structural features of the muscle fibers and the arrangement of the fiber bundles were, however, similar to those of the fetuses. 

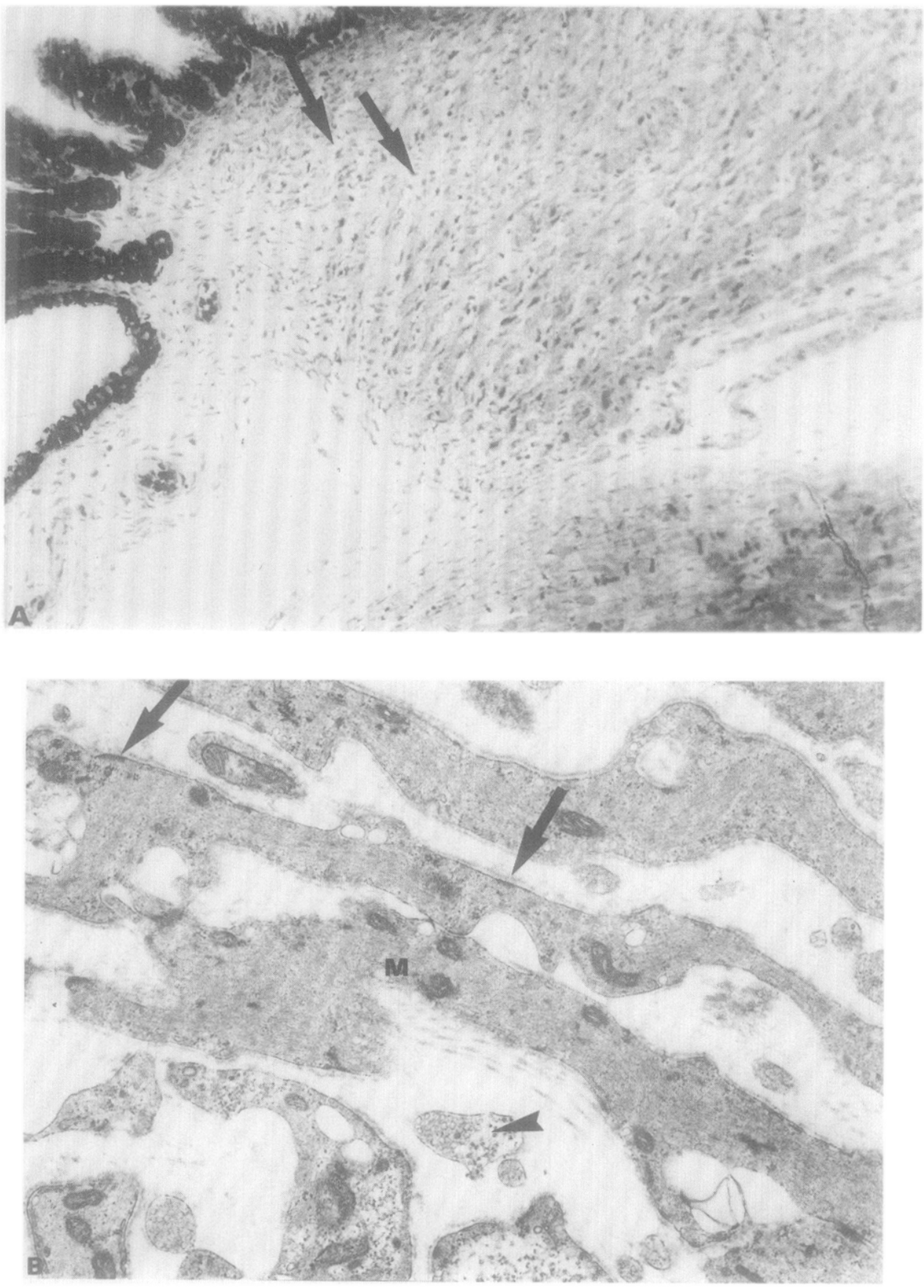

FIa. 1. (A) Sagittal section through the anterior part of the ciliary muscle of a 3 -wk-old rhesus monkey (Richardson stain, $\times 200)$. Note that the thin muscle bundles are separated from each other by loose connective tissue (arrows). The muscle bundles are oriented primarily longitudinally, and no pigmented cells are present between the hundles. (B) Electron micrograph of ciliary muscle cells (same monkey as in $(A), \times 15000)$. The muscle cells are filled with myofibrils, which are attached to the cell membrane by flat. dense bands (arrows). Only few mitochondria (MI) are visible. Between the muscle (ells. single nerve endings (arrowhend) are seet). 

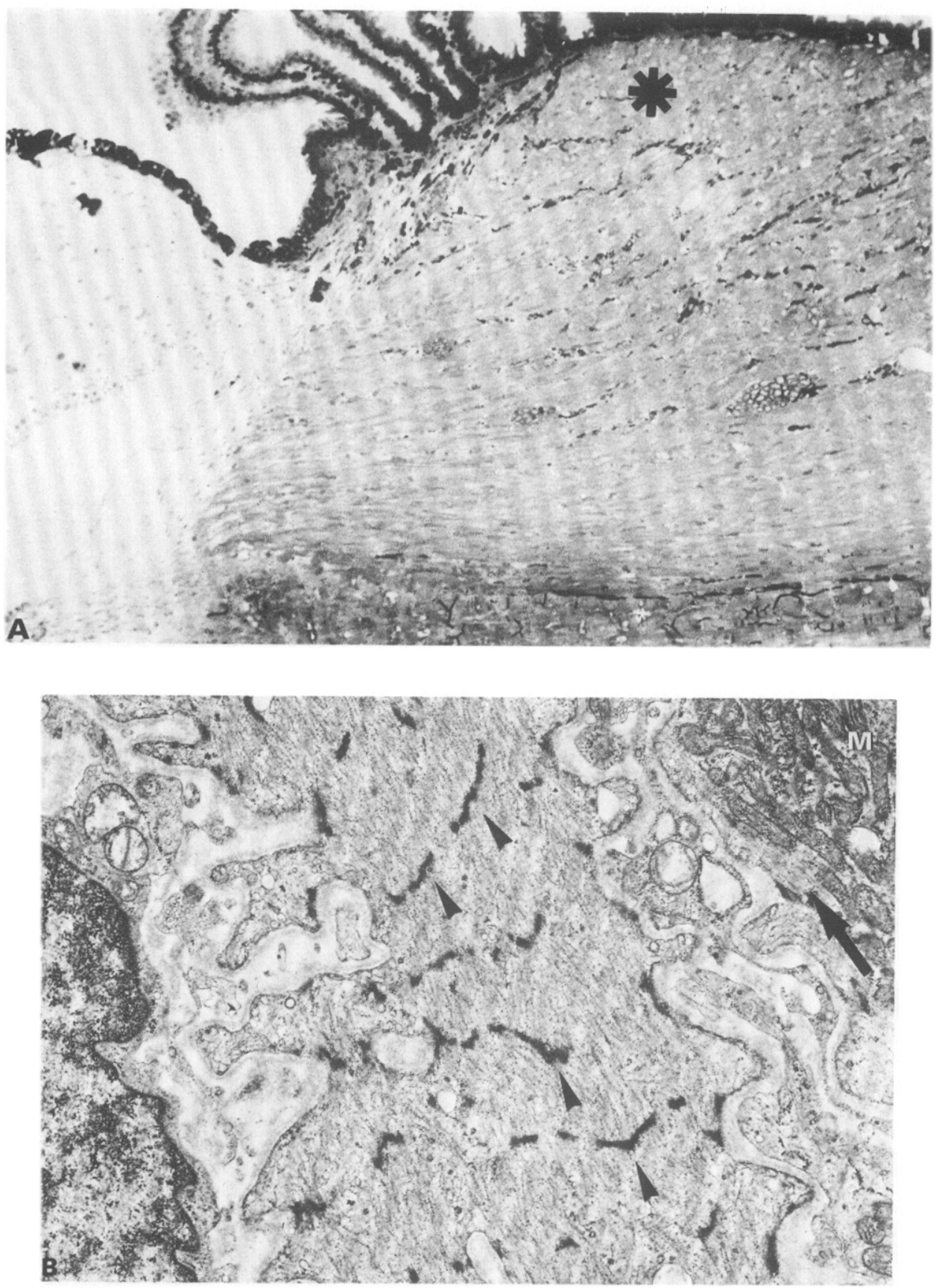

Fia. 2. (A) Sagittal section through the anterior part of the ciliary muscle of a $2-y-$ r-old rhesus monkey (Richardson stain, $\times$ 144). The thick muscle bundles lie close together and form a reticular portion at the inner edge (asterisk). Very little connective tissue is seen within the muscle. (B) Electron micrograph through a fully developed ciliary muscle cell $(4-y r-o l d$ monkey. $\times 6400)$. The center of the fiber is filled with mitochondria (M). while the myofibrils are located peripherally (arrow). If the muscle cell is cut tangentially, the $\mathrm{Z}$-bank-like dense bands are visible (arrowheads). The myofibrils are oriented almost in parallel. 
Age 1-4 yr. The muscle fibers were aggregated into thicker bundles and the muscle cells were connected to each other in all directions. Longitudinal. reticular and circular portions could be distinguished (Fig. 2(A)). In saggital section, the muscle showed a well-defined inner apex and the classic overall triangular configuration. Within each muscle bundle, the individual cells were packed tightly together. separated only by their respective basement membranes. the connecting fibrils between the basement membranes, and intervening nerve terminals. The entire bundle was surrounded by a thin collagenous sheath and a layer of perimysial cells.

The ultrastructure of the ciliary muscle cells was by now significantly different from that of smooth muscle cells of the vessel media, and exhibited the following characteristics. Numerous mitochondria filled the middle half of the cells, with myofibrils constituting the peripheral half (Fig. 2(B)). Dark osmiophilic elongated dense bands, similar to Z-bands of skeletal muscle. extended through the peripheral parts of the cells containing myofibrils (Fig. 2(B)) ; only the middle portion of the cells, containing the mitochondria, was free of dense bands. The muscle cells were branched, and were connected at discrete points, rather than over broad areas, by small desmosomes or maculae adhaerentes; gap junctions were difficult to study. because fixation and staining were not optimum for their detection. Numerous large. elongated nerve endings containing empty vesicles were seen lying adjacent to most muscle cells, but never penetrated the basement membrane.

Age 6-12 yr. Some individual muscle cells contained increased amounts of Golgi material, and some contained either lysosomes or 'fingerprints' (Fig. 3, Table II). Cells exhibiting 'fingerprints' appeared to have fewer myofibrils and shorter. less

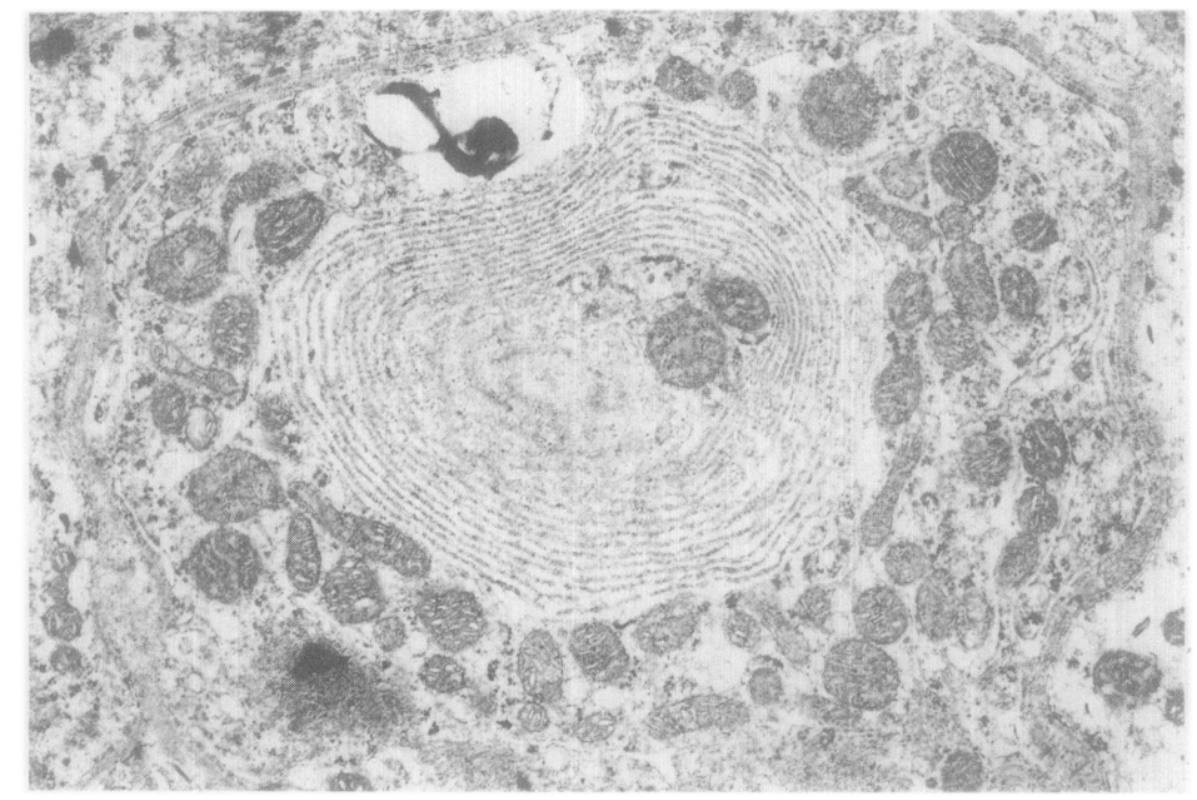

Fia. 3. Electron micrograph of a ciliary muscle cell showing 'fingerprint-like' arrangement of membranes in the center of the fiber. The number of cells showing these membranes increases with age. ('ells with 'fingerprints' contain fewer myofibrils $(12-y r$-old monkey, $\times 15000)$. 
visible dark bands. Some individual nerve endings and non-myelinated nerve fibers contained myelin figures, while some myelinated nerve fibers exhibited homogeneous inclusions.

These various alterations were not associated with one another. Each specific change was unevenly distributed around the circumference in the individual eye, i.e. present in some sections but absent in others. The alterations were also unevenly distributed among different portions of the muscle within a given section. Thus. 'fingerprints oceurred in the circular, reticular and posterior regions, but never in the anterior longitudinal portion (Table II). Light microscopically lysosomes appeared only in the circular and reticular zones and in single animals were not seen at all (Table I). However. electron microscopically. some were also seen in the longitudinal region.

Age 15-26 yr. In the reticular portion, the number of musele cells containing 'fingerprints' was increased, and for the first time 'fingerprints" sometimes were seen in the anterior longitudinal region (Table II). 'The 'fingerprints' were larger. and in cells containing them, there were fewer myofibrils than in the fingerprints'containing cells of younger animals. The proportion of muscle cells containing lysosomes or lipofuscin and the number and size of these organelles within such cells also increased (Fig. 4). Lysosome-containing cells were now present in all muscle regions of all sections. including in most eyes, even the anterior longitudinal portion (Table II). More nerve terminals and now Schwann rells contained myelin tigures, and degenerated myelinated nerve fibers were seen all around the circumference (Fig. 5). Macrophages containing large polymorphic inclusions were present within the nerve fiber bundles.

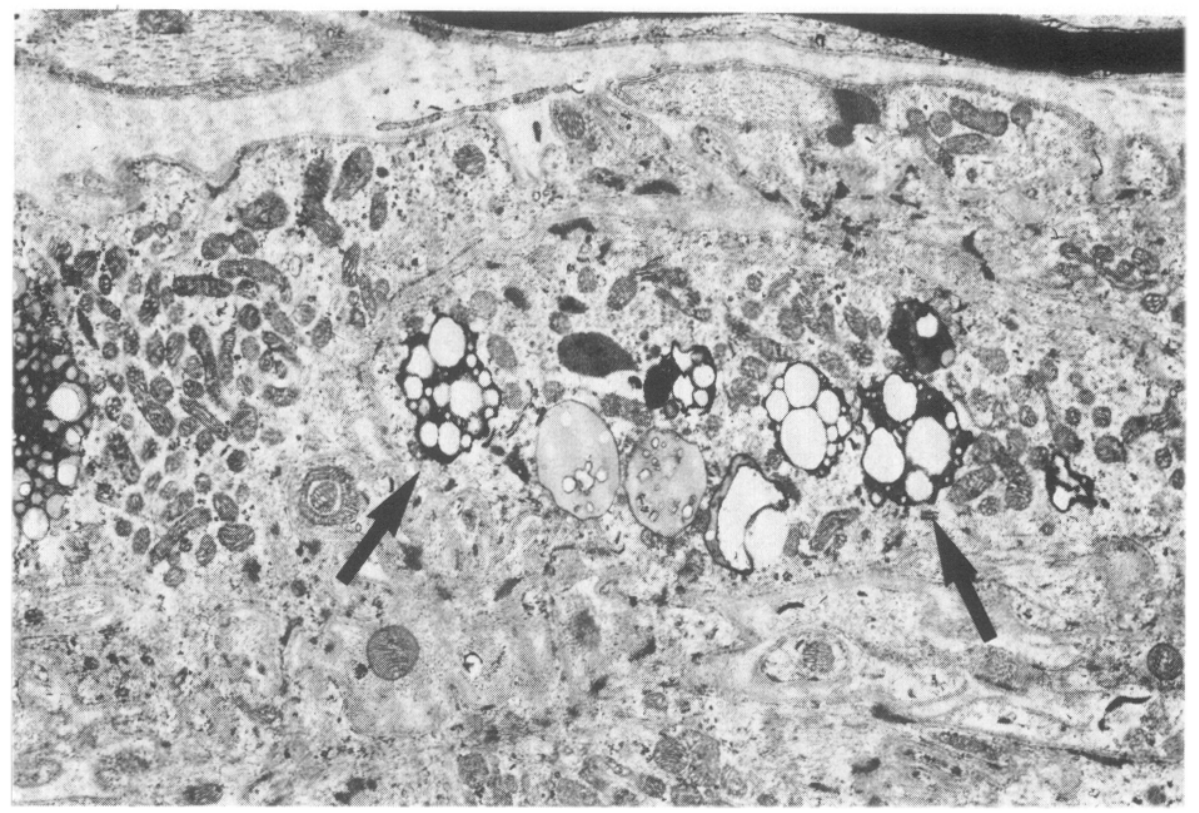

Fig. 4. Electron micrograph of a ciliary muscle fiber, showing large lysosomal inclusions (arrows) (26-yr-old monkey, $\times 7700)$. 


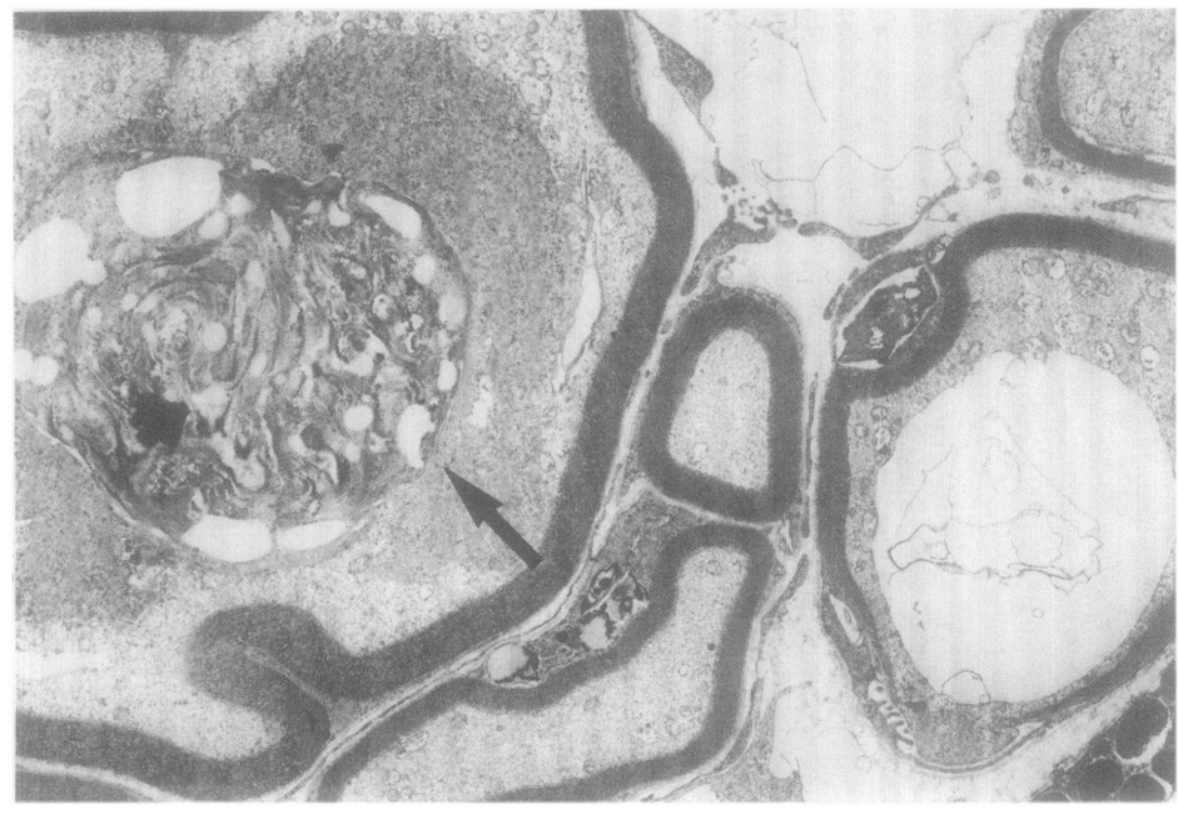

FIG. 5. Electron micrograph of myelinated nerve fibers within the ciliary muscle. The cytoplasm of the nerve tiber is filled with a large myelin figure (arrow) $26-$-rr-old monkey. $\times 60200)$.

Age 26-35 yr. The basement membranes of the muscle cells were thickened, so that in some places, the basement membranes of adjacent cells seemed to be fused. Many cells exhibited lateral microvilli-like extensions (Fig. 6). Some individual cells had degenerated, exhibiting hyalinization, 'fingerprint-like' myelin figures, and total absence of myofibrils and Z-band-like structures.

General note. Cells containing vacuoles and swollen mitochondria were occasionally present in all age groups. They seemed unrelated to age or systemic clinical/ pathologic findings, and were considered due to post-mortem autolysis.

\section{Connective tissue}

Intramuscular connective tissue did not increase until age $20 \mathrm{yr}$. Thereafter, small amounts of dense connective tissue (dense = numerous tightly packed collagen fibers with little intervening ground substance and few cells) separated only the anterior part of the longitudinal and reticular portions of the muscle. Dense connective tissue surrounding the neurovascular bundles became somewhat thicker, and the arteriolar bascment membranes also thickened. No hyalinized connective tissue was observed within the muscle, but beginning at age $15-20 \mathrm{yr}$, it was present in the thickened ground plate between the ciliary muscle and the iris root. These changes were all most pronounced in the very oldest animals (Fig. 7).

\section{Pigmented cells}

In the fetuses and in the 3 -wk-old neonate. no pigmented cells were seen within the ciliary muscle (Fig. 1(A)). In youth (age 1-4 yr) the muscle bundles were in places separated by rows of large cuboidal cells. the cytoplasm of which was densely packed 


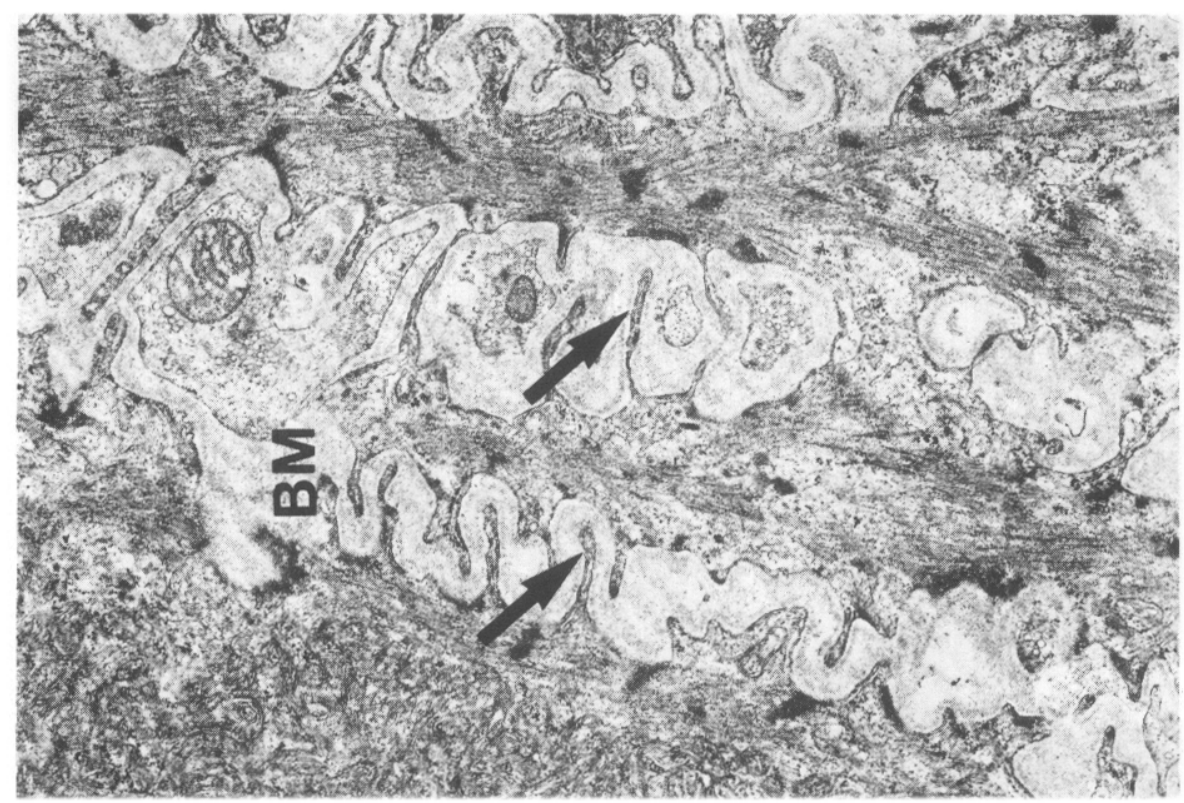

Fig. 6. Electron micrograph of ciliary muscle fibers in a 34-yr-old monkey. Note lateral microvilli-like extensions (arrow) and thickening of the basement membrane $(B M)(\times 8800)$.

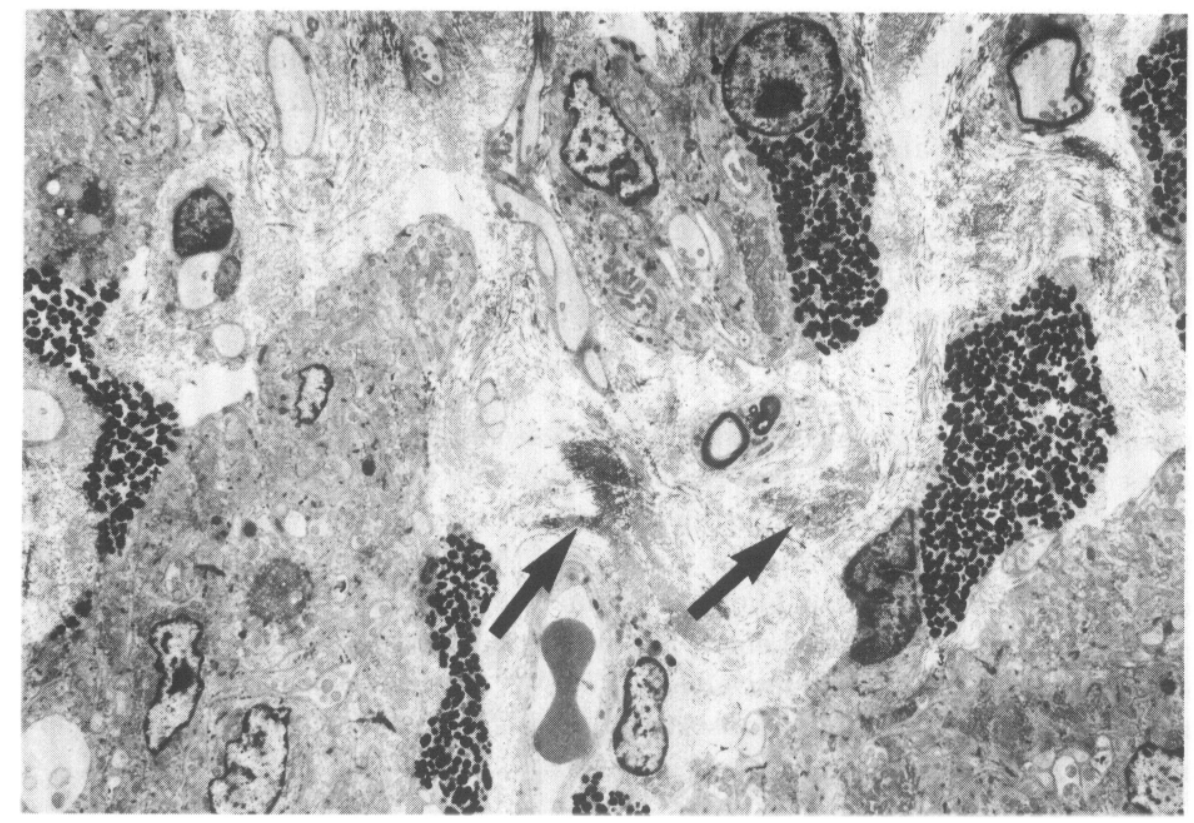

Fic. 7. Electron micrograph through an intramuscular space in the inner reticular portion of the ciliary muscle $(34-y r$-old monkey, $\times 1600)$. The spaces contain collagenous fiber bundles (arrows) and pigmented cells. 
with nearly homogeneously dispersed pigment granules of relatively uniform size. Some of these cells also contained lysosomes. The cells exhibited no or only small cytoplasmic extensions (Fig. 7). A complete basement membrane surrounding the cells was not seen (Fig. 7), but in places. structures similar to remnants of basement membranes were apparent. In eyes where only a few such cells were present, they were seen primarily at the iris root, beneath the pigmented epithelium in the anterior part of the ciliary processes, and in the choroid adjacent to the posterior end of the ciliary muscle. With increasing age, increasing numbers of such cells were found in the inner and posterior parts of the muscle. However. the spaces between the anterior tips of the outer longitudinal part of the muscle remained free of pigment up to age $20 \mathrm{yr}$. Beyond age $20 \mathrm{yr}$, the spaces between the muscle fiber bundles generally contained greatly increased numbers of pigmented cells compared to younger animals. Especially after age $25 \mathrm{yr}$, pigmented cells were present even between the tips of the anterior longitudinal portion of the muscle. so that these cells were interspersed throughout the entire muscle (Table I, Fig. 8).

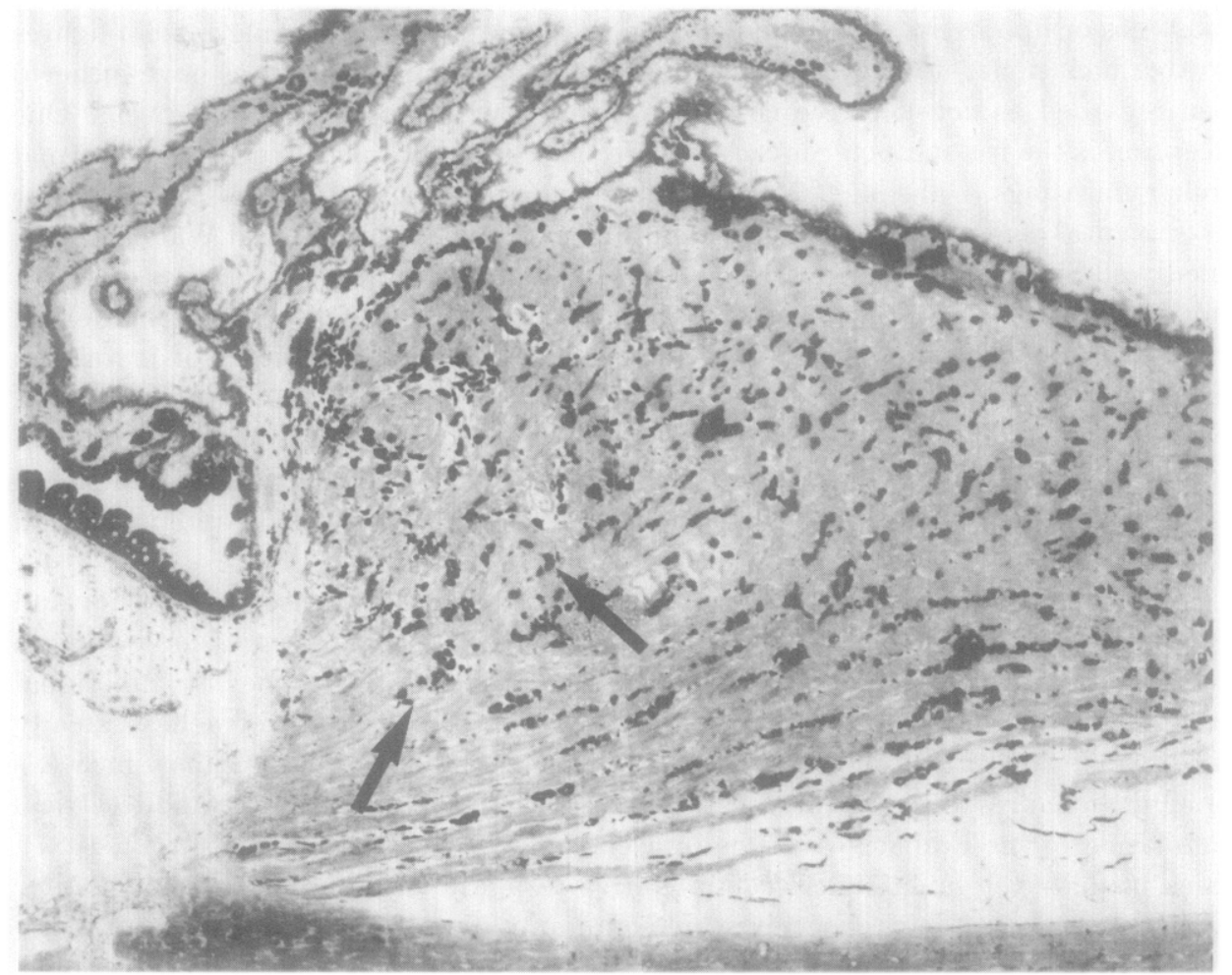

FIG. 8. Sagittal section through the ciliary muscle of a 30-yr-old rhesus monkey. Note that the spares between the muscle bundles are filled with pigmented cells (arrows) (Richardson stain. $\times 120$ ).

\section{Discussion}

\section{Ciliary neuromuscular apparatus}

The ultrastructure of primate ciliary muscle cells differs from that of gut or vascular smooth muscle cells in many respects (Ishikawa, 1962; van der Zypen, 1967). The almost parallel myofibrils, Z-band-like extensions of the dark bands, and dense 
innervation (Townes-Anderson and Raviola, 1978) all resemble striated skeletal muscles. as does the ciliary muscle's ability to contract and relax rapidly. Additionally, the large number of mitorhondria compared to the myofibrils is unique to ciliary muscle cells. This special functional morphology of the ciliary muscle cells is not seen in fetal or early neonatal life. At that stage. the muscle bundle system is not fully developed and would seem incapable of the complex remodeling and movement required for accommodation. In contrast, by age 1-2 yr the muscle cells already exhibit the distinctive ultrastructural characteristics which set the mature ciliary muscle apart from other smooth museles. The ciliary musele as a whole displays fully constituted fiber bundles, complete regionalization, a well-defined inner apex and the classic overall triangular configuration. At this age, the animals consistently accommodate the species' maximum of $>30$ diopters (Bito et al., 1982; Kaufman et al., 1983). The accommodative ability of perinatal rhesus has never been reported.

Degenerative changes first appear in the ciliary muscle at age $6 \mathrm{yr}$. At this age, they are infrequent and mild, with some muscle cells containing 'fingerprints' and lysosomes or lipofuscin, and some nerve endings and fibers containing myelin figures or other inclusions. 'Fingerprint-like' membranes or similar structures have hitherto been regarded as degenerative changes primarily within striated muscle cells. One exception is the iris sphincter muscle, where Gabella found such structures in normal adult guinea pigs (Gabella, 1974). In striated muscles, these structures appear after experimental denervation (Pellegrino and Franzini, 1963 ; Schrodt and Walker, 1966; Miledi and Slater, 1969) or are observed in certain human muscular diseases (Schutta and Armitage, 1969; Engel, Angelini and Gomez, 1972; Benke, 1976). The exact origin of these structures is not clear, but they seem to consist either of myofibrils which have lost their connection to the $Z$-band or of membranes normally located between the myofibrils. Increasing amounts of lipofuscin, lysosomes and myelin figures within axons have been described as being age-related changes in striated muscles (Gutmann, Hanzlikova and Vyskocil. 1971; Miller, 1975) and in human ciliary muscle (van der Zypen, 1970).

In the ciliary muscle of the rhesus monkey, these changes increase in frequency and severity up to age in the order of $\sim 25 \mathrm{yr}$, but little additional progression occurs in the last decade of life. This parallels the progressive decline in functional accommodative amplitude, which is quite pronounced by age 20 and reaches a steady nadir by age 25 (Bito et al., 1982; Kaufman et al., 1983). The rhesus ciliary muscle's configurational responses to pilocarpine (Lütjen-Drecoll et al., in press) and electrical stimulation of the Edinger-Westphal nucleus (Neider et al., 1986; Bito et al., 1987). which mediate the functional accommodative response, also diminish with age after maturity, reaching their relatively stable minimum by $\sim 25 \mathrm{yr}$. Thus, structural and functional deterioration in the accommodative apparatus begin concurrently, virtually as soon as the eye is fully mature, progress in parallel with age. and reach their maximum concurrently at $\sim 25 \mathrm{yr}$. This suggests that the ciliary muscle is somehow involved, either primarily or secondarily, in the pathophysiology of presbyopia in this species.

Age-related changes in the ciliary muscle fibers and intramuscular connective tissue observed by qualitative light microscopy seem insufficient to account for the dramatic loss of structural and functional responses (Lütjen-Drecoll et al., in press), but we had hoped that quantitative light and electron microscopy would be more revealing. We did indeed observe age-related neuromuscular alterations, but it is uncertain whether 
they account for the decreased responsiveness. There is no age-related decline in overall ciliary muscle muscarinic receptor concentration or affinity as measured by specific 3H-QNB binding (True-Gabelt, Polansky and Kaufman, 1987) [although relevant subpopulations could be affected without notice (Bito, Dawson and Petrinovic, 1971; Bárány, Berrie, Birdsall. Burgen and Hulme, 1982)], and no alteration in ciliary muscle choline acetyltransferase or acetylcholinesterase (TrueGabelt et al., 1987). Thus, while the available morphologic and biochemical data do not permit identification of a specific eiliary muscle-based pathophysiology for presbyopia. we cannot exclude the possible existence of functionally relevant biochemical, metabolic and morphologic changes within the ciliary neuromuscular apparatus which are undetectable by our current methods.

\section{Pigmented cells}

The absence of pigmented cells between the ciliary muscle bundles of the youngest animals and the increasing number of such cells with age has implications outside the context of presbyopia.

Morphologically, the pigmented cells resemble the iris clump cells of Koganei (Koganei, 1885), which according to Wobmann and Fine (Wobmann and Fine, 1972) can be subdivided into Type 1 and Type 2 cells. These latter authors consider the origin of the clump cells to be macrophages or iris pigment epithelium itself (Type 1 ). or arrested stages of developing neuroepithelial cells (Type 2). Type 2 cells are surrounded by a complete basement membrane and have junctional structures (Wobmann and Fine, 1972). In our material, Type 2 cells were not seen. Like the Type 1 cells. the clump cells in the aged rhesus ciliary muscle resembled pigment epithelium or macrophages which had ingested pigment granules. In contrast to the human. where clump cells are only seen within the iris (Lauber. 1936), in aging rhesus monkeys these cells are found mainly within the ciliary muscle. In aging human eyes. the spaces between the ciliary muscle bundles are filled with large amounts of hyalinized connective tissue. which might prevent the cells from entering the muscle.

In the ciliary muscle of the young monkeys. the clump cells first appear just beneath PE of the anterior part of the ciliary processes, concurrently with and adjacent to the earliest depigmentation of the ciliary PE (E. Lütjen-Drecoll, unpubl. data). With increasing age, similar cells fill the spaces between the muscle bundles of the circular and reticular regions of the ciliary muscle. as depigmentation of the ciliary PE progresses posteriorly within the pars plicata. However, the anterior part of the outer longitudinal region is spared until age $20 \mathrm{yr}$. after which the pigmented cells are dispersed throughout the entire ciliary muscle and the ciliary PE shows patchy depigmentation along its entire length ( $\mathrm{F}$. Liitjen-Drecoll, unpubl. data).

Collectively, these findings lead to the hypothesis that the cells: (1) become trapped in the poorly irrigated circular and reticular regions of the ciliary muscle; (2) are carried away from the better irrigated anterior longitudinal region by uveoscleral outflow of aqueous kumour, which traverses this region preferentially (Inomata, Bill and Simelser, 1972); and (3) accumulate even in the anterior longitudinal region in older age because $(a)$ they are shed from the ciliary PE in much greater quantity and/ or $(b)$ the rate of uveoscleral flow decreases. 


\section{AC'KNOWLEDGMENTS}

Patrick Goeckner, B'Ann True-Gabelt. and Kathryn ('raw ford obtained and fixed the eves in Madison; Karin Junge. Elke Kretschmar and (iertrud Link processed the tissues and Mareo Gö $\beta$ wein prepared the figures in Erlangen. We are especially grateful to the staff of the Wisconsin Regional Primate Research Center for their co-operation and assistance in making these specimens available to us.

This study was supported by grants from the Deutsche Forschungsgemeinschaft(no. Dr $124 / 2-3)$. the Mainzer Akademie der Wissenschaften and from the USPHS National Institutes of Health (nos. EY04146. TW01044 and RRo0167).

\section{REFERENCES}

Bárány, E. H., Berrie, C. P., Birdsall, N. J. M.. Burgen. A. S. V. and Hulme, E. (. (1982). The binding properties of the muscarinic receptors of the cynomolgus monkey ciliary body and the response to the induction of agonist subsensitivity. Br. J. Pharmacol. 77. $731-9$.

Benke, B. (1976). Mass oceurrence of multilamellar bodies in myopathy. V'irchows Arch. B Cell. Pathol. 20, 77-84.

Bito. L. Z., Dawson, M. J. and Petrinovic, L. (1971). Cholinergic sensitivity: normal variability as a function of stimulus background. Science 172, 583-5.

Bito, L. Z.. DeRousseau, C. J., Kaufman, P. L. and Bito, J. W. (1982). Age-dependent loss of accommodative amplitude in rhesus monkeys: an animal model for presbyopia. Invest. Ophthalmol. Vis. Sci. 23, 23-31.

Bito, L. Z., Kaufman, P. L., Neider, M., Miranda, O. C. and Antal, P. (1987). The dynamies of accommodation (eiliary muscle contraction, zonular relaxation and lenticular deformation) as a function of stimulus strength and age in iridectomized rhesus eyes. Invest. Ophthalmol. Vis. Sci. 28 (ARVO Suppl.), 318.

Engel, A. G., Angelini, C. and Gomez, M. R. (1972). Fingerprint body myopathy-a newly recognized congenital muscle disease. Mayo Clin. Proc. 47, 377-88.

Gabella, G. (1974). The sphincter pupillae of the guinea-pig: structure of muscle cells, intercellular relations and density of innervation. Proc. R. Soc. Lond. B 186, 369-86.

Gutmann, E., Hanzlikova, V. and Vyskocil. F. (1971). Age changes in cross-striated muscle of the rat. $J$. Physiol. 219, 331-43.

Inomata, H., Bill, A. and Smelser, G. K. (1972). Uneonventional routes of aqueous humor outflow in the cynomolgus monkey (Macaca irus). Am. J. Ophthalmol. 73, 893-907.

Ishikawa, T. (1962). Fine structure of the human ciliary muscle. Invest. Ophthalmol. 1. $587-608$.

Ito, S. and Karnovsky, M. J. (1968). Formaldehyde-glutaraldehyde fixatives containing trinitro compounds. J. Cell Biol. 39 (22), 168a.

Kaufman, P. L. and Bito. L. Z. (1982). The occurrence of senile cataracts, ocular hypertension and glaucoma in rhesus monkeys. Exp. Eye Res. 34. 287-91.

Kaufman, P. L., Bito, L. Z. and DeRousseau, C. J. (1983). The development of presbyopia in primates. Trans. Ophthalmol. Soc. U.K. 102, 323-6.

Koganei, J. (1885). Untersuchungen über den Bau der Iris des Menschen und der Wirbelthiere. Archiv Mikroskop. Anatomie 25, 1-47.

Lauber, H. (1936). Haut und Sinnesorgane. In Handbuch der Mikroskopischen Anatomie des. Menschen. (Ed. Möllendorf, Wv.). Vol. II/2, pp. 134-82. Springer: Berlin.

Lütjen-Drecoll, E. (1973). Structural factors influencing outflow facility and its changeability under drugs: a study of Macaca arctoides. Invest. Ophthalmol. 12, 280-94.

Luitjen-Drecoll, E., Tamm, F. and Kaufman. P. L. (1988). Age-related loss of morphologice responses to pilocarpine in rhesus monkey ciliary muscle. Arch. Ophthalmol. (in press).

Miledi, R, and Slater, C. R. (1969). Electron-microscopic structure of denervated skeletal muscle. Proc. Soc. London Ser. B 174, 253-69.

Miller, .J. E. (1975). Aging changes in extraocular muscle. In Basic Mechanisms of Ocular Motility and Their Clinical Implications. (Eds Lennerstrand, G. and Bach-y-Rita. P). Pp. 47-61. Pergamon Press: Oxford. 
Neider. M. W., Crawford, K. True-Gabelt, B., Kaufman, P. L. and Bito, L. Z. (1986). Functional studies of accommodation and presbyopia in thesus monkeys. Inrest. Ophthalmol. Vis. Sci. 27. (ARVO Suppl.), 81.

Pellegrino, C. and Franzini, C. (1963). An electron microscope study of denervation atrophy in red and white skeletal muscle fibers. J. Cell Biol. 17, 327-49.

Schrodt, G. R. and Walker. S. M. (1966). Cltrastructure of membranes in denervation atrophy. Am. J. Pathol. 49, 33-51.

Schutta. H. S. and Armitage, J. L. (1969). Thyrotoxic hrpokalemic periodic paralysis : a fine structure study. J. Neuropathol. Exp. Neurol. 28. 321-36.

Townes-Anderson, E. and Raviola, G. (1978). Degeneration and regeneration of autonomic. nerve endings in the anterior part of rhesus monkey ciliary muscle. Neurocytol. 7 , $583-600$.

True-Gabelt, B.. Polansky, J. R. and Kaufman. P. I. (1987). (iliary muscle muscarinic receptors. ChAt and AChE in young and old rhesus monkeys. Incest. Ophthalmol. Ii.s. Sci. 28 (ARVO Suppl.), 65.

Wobmann, P. R. and Fine, B. S. (1972). The clump cells of Koganei : a light and electron microscopic study. Am. J. Ophthalmol. 73, 90-101.

van der Zypen, E. (1967). Licht- und elektronenmikroskopische ('ntersuchungen über den Bau und die Innervation des Ciliarmuskels bei Menseh und Affe (C'ercopithecus aethiops). Albrecht v Graefes Arch. Klin. Exp. Ophthalmol. 174, 143-68.

van der Zypen, E. (1970). Licht- und elektronenmikroskopische Untersuchungen über die Altersveränderungen am $M$. ciliaris im menschlichen Auge. Albrecht v Graefes Arch. Klin. Exp. Ophthalmol. 179, 332-57. 